\title{
Participatory involvement of farming communities and public sectors in determining malaria control strategies in Mvomero District, Tanzania
}

\author{
M.R.S. MLOZI ${ }^{*}$, E.H. SHAYO ${ }^{2}$, K.P. SENKORO², B.K. MAYALA², S.F. RUMISHA ${ }^{2}$, \\ B. MUTAYOBA ${ }^{2}$, E. SENKONDO ${ }^{1}$, A. MAERERE ${ }^{1}$ and L.E.G. MBOERA ${ }^{2}$ \\ ${ }^{1}$ Sokoine University of Agriculture, P.O. Box 3002, Chuo Kikuu, Morogoro, Tanzania \\ ${ }^{2}$ National Institute for Medical Research, P.O. Box 9653, Dar es Salaam, Tanzania
}

\begin{abstract}
Addressing the malaria-agriculture linkages requires a broad inter-disciplinary and integrated approach that involves farming communities and key public sectors. In this paper, we report results of participatory involvement of farming communities in determining malaria control strategies in Mvomero District, Tanzania. A seminar involving local government leaders, health and agricultural officials comprising of a total of 27 participants was held. Public meetings in villages of Komtonga, Mbogo, Mkindo, Dihombo and Luhindo followed this. Findings from a research on the impact of agricultural practices on malaria burden in the district were shared with local communities, public sector officials and other key stakeholders as a basis for a participatory discussion. The community and key stakeholders had an opportunity to critically examine the linkages between agricultural practices and malaria in their villages and to identify problems and propose practical solutions. Several factors were identified as bottlenecks in the implementation of malaria control in the area. Lack of community participation and decision making in malaria interventions was expressed as among the major constraints. This denied the community the opportunities of determining their health priorities and accessing knowledge needed to effectively implement malaria interventions. In conclusion, this paper emphasizes the importance of participatory approach that involves community and other key stakeholders in malaria control using an ecosystem approach. An interdisciplinary and integrated approach is needed to involve farmers and more than one sector in malaria control effort.
\end{abstract}

Key words: community, participatory, agriculture, malaria, ecosystem, Tanzania

\section{Introduction}

Malaria remains a major public health problem in subSaharan Africa. Of the 300-500 million annual episodes of malarial illness globally and over a million deaths, $90 \%$ occur in Africa. The most affected groups of population are pregnant mothers and children under the age of 5 years (Samba, 2001). The consequences of such high rates of malaria go far beyond health to affect the economic circumstances of communities, and, in turn, the development prospects of the districts or countries in which malaria is endemic.

Malaria has major and multifaceted linkages with agriculture (Klinkenberg et al., 2005). The linkages make farming communities in a malaria endemic area to have a central position in creating or controlling the conditions that favour disease transmission (van den Berg \& Knols, 2006). Despite the fact that community involvement is an important component for any disease intervention, malaria control in Tanzania has largely been the responsibility of the Ministry of Health and District Health Management Teams (DHMT) with little involvement of the community and other sectors of the economy. There is now increasing realization that multi-sectoral approaches that involve the community are essential components in any malaria control strategy (Mukabana et al., 2006).
Community participation is usually conceptualised as a process by which people (i.e. members of communities) individually or collectively assume increased responsibility for assessment of their own health needs, and once these are agreed upon, identify potential solutions to problems, and plan strategies by which these solutions may be realised (Bermejo \& Bekui, 1993). The importance of active participation and empowerment of rural communities to the effective malaria control interventions and to the sustainability of their outcomes is well documented by Espino et al. (2004).

With increasing recognition of the value of and need for working with local communities to identify, test, evaluate and disseminate new disease intervention and agricultural technologies, various participatory approaches have been taken by various organizations (Chambers, 1992). Despite the benefits of involving communities accrued from various development programmes, little has been done in involving farming communities of Tanzania in deciding on the appropriate malaria control strategies in the context of their environments. We report in this paper a participatory process used to involve local government leaders, professionals, researchers and communities in determining malaria control strategies in Mvomero District, Tanzania. This is part of larger study on the impact of agricultural practices on malaria burden in Mvomero District, Tanzania. 


\section{Materials and Methods}

\section{Study area}

The study was conducted in Mvomero District, Tanzania $\left(5^{\circ} 80^{\prime}-7^{\circ} 40^{\prime} \mathrm{S} ; 37^{\circ} 20^{\prime}-38^{\circ} 05^{\prime} \mathrm{E}\right)$ lying at $300-400 \mathrm{~m}$ above sea level. The average maximum and minimum in temperature is $30^{\circ} \mathrm{C}$ and $20^{\circ} \mathrm{C}$, respectively, with an average rainfall of $1146 \mathrm{~mm}$ per year. The District is made up of four divisions, 17 wards, and 128 villages covering an area of 14,004 $\mathrm{km}^{2}$. According to the National Census of 2002, the district population was 260,525 and made up of 58,314 households (URT, 2003). The district is served by 45 health facilities (three hospitals, three health centres and 39 dispensaries). Economically, the district depends on sugarcane, rice, maize and sorghum cultivation. Livestock keeping is common among the pastoralists.

\section{Participatory approach and involvement of community and key public sectors}

A seminar was conducted at Mkindo Farmers Training Centre, Mvomero District involving a total of 27 participants. These included officials from the district Health, Agriculture and Livestock sectors. Other participants included Division Secretaries, Ward Executive Officers, Agricultural Trainers, Health Officers, Agricultural Extension Officers and a Journalist. Researchers from the National Institute for Medical Research and Sokoine University of Agriculture facilitated the seminar.

The seminar aimed at identifying problems related to malaria and farming practices in view of designing appropriate control measures. Participation of the various stakeholders denoted the active involvement of a significant number of persons in situations or actions to enhance their well-being. There was a voluntary contribution of the people in a dialogue, but without researchers taking part in decisionmaking. The different stakeholders, had opportunities to present their views and recommendations, and also to comment on those presented by other stakeholders. Researchers were clear that the participatory process needed to be carefully facilitated in order not to raise unrealistic expectations or create tensions, which could not be resolved.

Public meetings (Figures 1 and 2) were thereafter conducted in villages of Komtonga, Mbogo, Mkindo, Dihombo and Luhindo to discuss the malaria problem and share with communities the research findings. Researchers, Ward and Division Secretaries facilitated the public meetings. The request to hold the public meeting was conveyed to the Village Executive Officer two weeks before the date of the meeting. A reminder was also conveyed a day prior to the meeting.
During the seminar and public meetings, presentations and discussions were made on (i) malaria situation in the country and Mvomero District, (ii) the objective, rationale, and findings of the research on linkages of malaria and agriculture; and (iii) role of community in malaria prevention and control. Thereafter, participants were given opportunity to ask questions, discuss and propose solutions to the identified problems. Discussions on the problems and solutions focused on the role of various sectors, particularly, health, agriculture, research institutions and communities in malaria control and improvement of agricultural practices.

\section{Results}

\section{Constraints in malaria control}

The main problems that contributed to increased malaria incidence in Mvomero were identified to include low capacity of health workers to diagnose and manage cases of malaria, lack of an appropriate health education and implementation of inappropriate malaria control strategies by the district officials. It was also described that the few available health workers were mostly occupied with un-official activities including farming and business to complement their salaries. Increased of malaria incidence was also attributed to poor health care services provided. Inadequate drug supply at the health facilities prompted some of community members to buy drugs from drug stores for home medication or to consult traditional healers. Poor client-health care provider interaction and lack of laboratory services were claimed to be common in the district. Inequity was also identified as a constraining factor in obtaining good health service. The cost for health services was said to be beyond the ability of many farmers.

On the other end, participants identified inappropriate rice irrigation practices as the main factor that contributes to increased malaria transmission in their areas. Growing of rice in bunds was associated with increased mosquito density, as water would remain in the field long enough for mosquito to breed. Farm activities, such as planting, weeding, scaring birds, and harvesting, were also mentioned to put people at risk of acquiring malaria infection. Other farming practices including spacing between plants, orientation of crop lines against wind and/ or sun, were mentioned to favour insect harbourage. Poor drainage in farms was another area of concern in malaria transmission as to allow continuous mosquito breeding. Most participants associated such poor farming practices, which favour mosquito productivity with high incidences of malaria in their communities. 
The community blamed health and agricultural extension workers for their failure to provide education on good crop and animal husbandry, which would have inadvertently reduced the malaria transmission. Agricultural extension officers admitted to rarely providing education on appropriate farming practices. There was a strong feeling among participants that perhaps agricultural extension officers had inadequate knowledge on the linkages between agriculture and malaria. This thinking was attested during the seminar where it was revealed that knowledge of linkages of agricultural practices and health are not included in the training curricula of agricultural and medical training institutions.

Observations made by the communities themselves revealed that there were abundant areas that supported mosquito breeding in their house surroundings. These included remains of tins, coconut shells, and pools of water. Poor environmental sanitation was common in most of the villages and this was also attributed to play a role in supporting mosquito breeding.

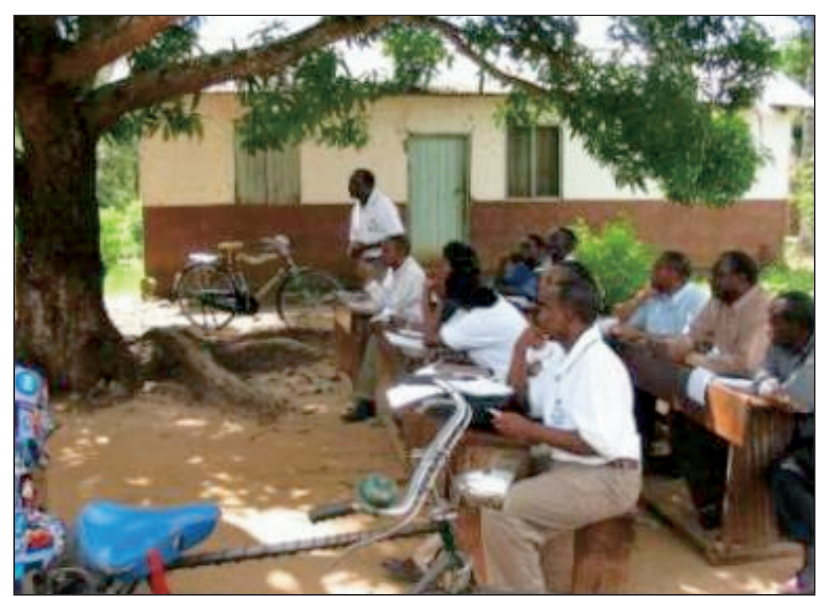

Figure 1: A group of scientists presenting research findings during a public meeting at Mbogo village

The participants commended the recent introduction of voucher scheme in scaling-up the use of insecticide treated nets (ITNs). However, they complained of the procedures used to distribute ITNs through the scheme (TNVS, 2006). According to the community members, the scheme only allows for a few mothers to access the service, because after getting the voucher card, they have to ask money from their husbands. Moreover, even when mosquito nets were available in the households their use was restricted leaving most members of the household unprotected. In addition, most community members were sceptical of the mechanism used to implement the scheme. Since, many households could not pay for the nets, participants requested the Government to provide free mosquito nets to vulnerable poor communities.

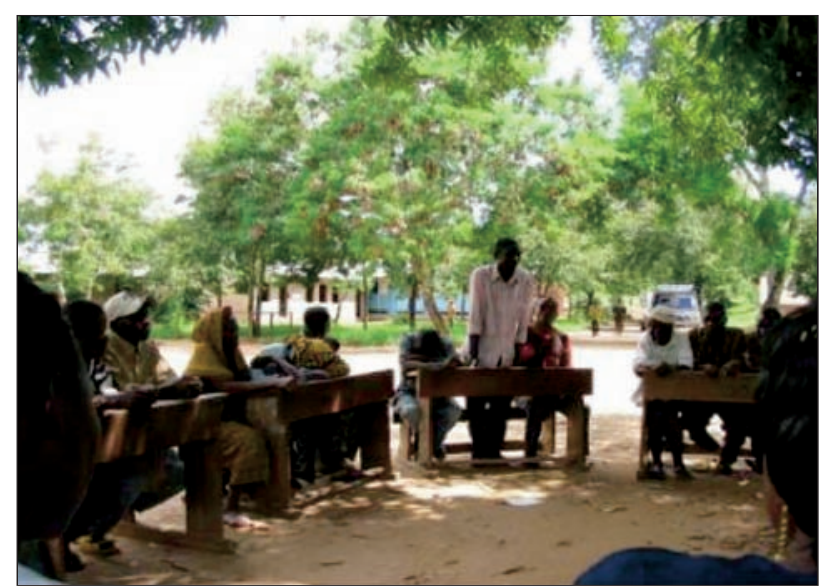

Figure 2: A farmer making a point during one of the discussions

Participants admitted that there has been substantial improvement in use of proper spacing in rice cultivation. However, correct row orientation was not observed thus creating favourable environment for mosquito harbourage. They alluded to the fact that most of the advice given by the agricultural and livestock extension officers had been on improving crop yields, and none on row orientation and that such education was important and should be included in future farmers' training programmes.

During the discussion, it was revealed that despite substantial income revenue obtained from agricultural produce (especially rice harvest), many families, especially from Komtonga, put low priority on malaria control in respect to total household budgeting. Many participants alluded to the fact that they had little income that could be spent to cover costs of malaria control for the whole year. They affirmed that most people in the villages lacked knowledge on appropriate budgeting. It was also realised that in some villages, with improved farming and farmer's economy, farmers spent their money in post-harvest entertainments such as traditional dances than in health issues. Such households were even hiring and bringing dancing groups (Mchiriku) from as far as Dar es Salaam (about $240 \mathrm{~km}$ away), and would take several days feasting and dancing. Such entertainments were said to consume a large proportion of the harvests and money.

Poverty was said to contribute to disease burden in the district. Most of the community members lived below the poverty line and were unable to pay for health care services. The community was aware of the fact that poverty was one of the reasons for increased disease burden in their households.

Participants discussed some of the mass media advertisements, which were disturbing and misleading. For example, they questioned the authenticity of the television (TV) advertisements, which purports to show that the whole country was 
covered by a large mosquito net (Figure 3). Participants also wanted to know about malaria mosquitoes biting patterns. They queried on the reliability of the information provided by some television adverts that mosquito bites only at midnight. They rejected the authenticity of this advertisement as they alluded to being beaten by mosquitoes even during the daytime, dusk or dawn. The researchers gave clarification on mosquito biting behaviour.

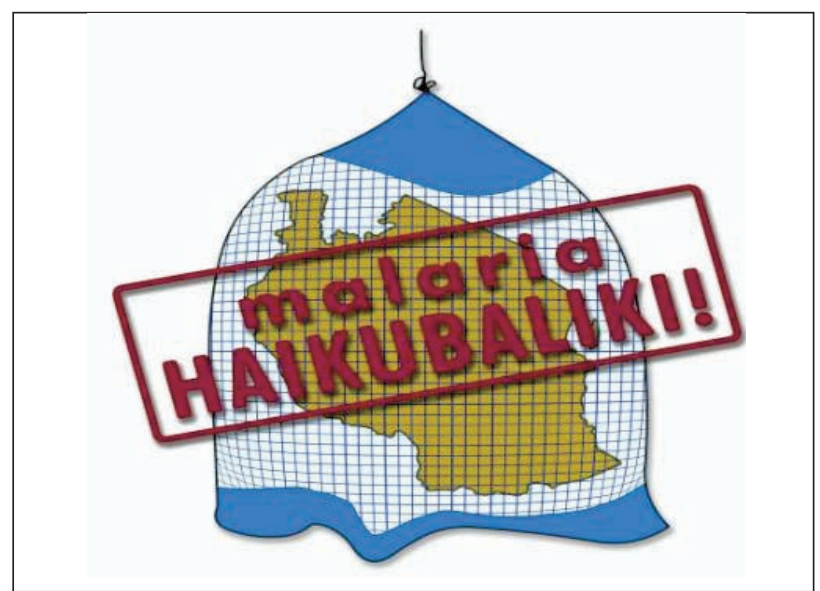

Figure 3: A TV advertisement with "Tanzania" completely covered by mosquito net

Although most participants agreed that $\mathrm{NGAO}{ }^{\circledR}$ (the insecticide used to treat nets) was effective against malaria mosquitoes, some disapproved its use. There was a consensus that inappropriate use of the insecticide by many households rendered the insecticide ineffective against mosquitoes. Community members mentioned misuse of the insecticide was common among crop and livestock farmers. There were claims that livestock keepers were using the insecticide to spray cattle against ticks and tsetse fly, while crop farmers were spraying crops against pests (e.g. maize stalk borers, aphids or stem borers). It was eluded that health workers and agricultural extension officers were not providing education on the dangers to human health or environmental pollution as a result of misuse of the insecticides. It was agreed that, although the manufacturers' instructions were self-explanatory, most community members were not knowledgeable on the best way to dispose the insecticide remaining after net treatment.

There was an observation that one of the reasons for the community to strictly participate in malaria control effectively was lack of enforcement of the bylaws. It was observed that most of the local council by-laws that purported to institute good practices for mosquito control were not enforced mainly because of poor governance.

\section{Proposed strategies}

Community members agreed that the number of malaria cases could be reduced through proper drainage of the rice fields. However, this was found to be difficult to implement given the scattered nature of most of the rice fields, as well as the fact that rice was grown on bunds. Farmers' education on good farming practices that do not support mosquito productivity was identified by participants as crucial in reducing the incidence of malaria in their areas.

Participants agreed that most farmers performed the post-harvest farm clearing by burning the crop residues instead of burying them to enrich the soil for the next season's crops. Community members alluded to the fact that burying crop residues were to be stressed by the agricultural and livestock extension officers. Post-harvest farm clearing was perceived to be time consuming, especially if all the crop residues had to be buried to replenish soil fertility. Consensus was later reached that post-harvest farm clearing was important and should be done by all villagers to help to keep at bay mosquitoes, and reduce incidences of malaria transmission.

Participants wanted the government to take extra effort to promote the inclusion of Azolla in rice farming. Azolla was common in some rice farms particularly at Mkindo and Dihombo and was introduced as a biological fertiliser. Community members welcomed the idea of using Azolla because of its multiple functions as a fertilizer and as a biological control against breeding of mosquitoes. They proposed that all rice farming communities to incorporate Azolla in their rice fields. However, it was agreed that further research on Azolla and its effects on rice productivity and malaria mosquito breeding should be carried out to provide strong basis for its expansion in rice farms. Members also expressed the desire to collaborate with health, agriculture and social researchers in evaluating the usefulness of Azolla.

Participants were of the opinion that researchers had the duty to provide communities with current appropriate knowledge and information that could be utilised in malaria prevention and control. They blamed most projects for not providing feed back of their community-based studies. Participants commended the efforts made by this research team for sharing their research findings with the community and other stakeholders.

Community members stressed the importance of maintaining good hygiene among household members. To control malaria, the community was of the opinion that re-training of health staff on appropriate malaria management; making antimalarial drugs available in public health facilities and appropriate community health education would reduce malaria burden in their area. It was agreed that education on rational household income allocation 
was also important if malaria control was to be given its due importance among household members. Community member expressed their desire to cooperate to enrol themselves with the farmers training programme on improved agriculture. They also pledged the village governments to re-enforce by-laws on sanitation and proper environmental management, with special emphasis on malaria control.

\section{Discussion}

The participatory approach used in this study provided a useful way of meeting three things. First, stakeholders rapidly identified the range of potential impacts through exploring the inter linkages between different dimensions of agricultural practices and malaria in the area. Second, prioritising the different possible impact goals for assessment by identifying a range of possible impacts was most important for the primary stakeholders e.g. increased food security versus mitigating malaria or the levels of income versus household priorities. Third, identifying reliable measurable or qualitative indicators, which could be used to control malaria in different contexts by different target groups. Moreover, the fact that effective interventions were available but enforcement of by-laws was necessary was identified as one of the appropriate strategy to be adopted.

Several factors have been identified as bottlenecks in the implementation of various disease control interventions in the country (Mboera et al., 2005). In this study, the farming communities expressed lack of community participation and decision-making in malaria interventions. Community participation and involvement of various public sectors created a partnership in malaria control in relation to farming practices. The principle of partnership in strengthening the health system has also been demonstrated in other areas of East Africa (Mukabana et al., 2006). However, with all such experiences, it remains to be seen whether community based malaria interventions can be cost-effective and sustainable. Recently, in Rufiji, Morogoro and Mvomero, Tanzania, the districts, in collaboration with Tanzania Essential Health Interventions Project, have been working to strengthen the health system with community participation. Village health committees and partners drew up plans that could be developed with resources from the Ministry of Health and partners active in the districts. This led to a significant improvement of health services in all health facilities (http://www.idrc.ca/en/ev)
It is envisaged that by involving community and different key stakeholders in strategizing control measures will empower the community in deciding what is appropriate and what is feasible (Ahmed, 1978; Woelk, 1992). Usually, community participation involves a spectrum of processes, including organization, planning, evaluation, cooperation and contribution of time, labour, and resources by the community itself (Espino et al., 2004). It has been established that many communities across Africa are active and determined to implement malaria control through their own community-basedorganisations but have little access to the basic information and training which would enable them to do so (Mukabana et al., 2006).

Most of the disease control programmes in Tanzania are implemented vertically from the central government (Ministry of Health) through the district council with little involvement of the targeted community. Usually, community participation is limited in regards to determining health care priorities and the knowledge they need to implement the proposed interventions. It needs to noted that community involvement in disease control programmes is crucial because national or district health officials often perceive the needs of communities differently from communities themselves (Woelk, 1992; Mboera, 1998). Most often, and despite the rhetoric of self-determination, communities are compelled to implement strategies determined independently of them.

Community participation emphasizes the "bottom up" approach in planning and implementation of intervention programmes, where people are seen as active participants, compared to the conventional "top down" approach, where people are considered as passive recipients of programmes designed for them by professional and government officials (Oakley, 1989). Partnership between professionals and people generating health information through participatory planning is crucial for community participation as observed in this study and other studies in Tanzania (Mboera et al., 2005).

Use of Azolla and possibility of the introduction of intermittent irrigation were some of the issues raised by researchers as some of the farming practices that can be used to improve agricultural productivity and reduce mosquito productivity. This plant is known to reduce oviposition and adult emergence of malaria mosquitoes (Mogi et al., 1986; Rejendraan \& Reuben, 1988). However, the communities lacked such information. It is noteworthy that educational investment in agriculture can indirectly benefit health 
in general and malaria in particular. Already, farmer's field school programmes in malaria endemic areas have inadvertently influenced malaria epidemiology if income and living standards are raised (van den Berg \& Knols, 2006).

In order to help communities develop appropriate malaria control interventions, the involvement of various public sectors including health, agriculture, community development and natural resources is important. These sectors are expected to contribute their knowledge and experience to improving local skills and abilities so that the community itself can make decisions and take the actions that they believe are essential for their own development in their local context. This study has provided a rare opportunity to develop a truly interdisciplinary research agenda on agriculture and malaria and to involve farming community in developing strategies to improve agricultural practices and malaria control. Moreover, the involvement of public sectors, research institutions and the communities ensured a holistic approach in identifying problems and appropriate strategies.

In conclusion, malaria prevention must go hand in hand with community and inter-disciplinary participation. Unless individuals in communities and other key stakeholders see the merits of preventing the illness, even the best-designed prevention strategies are unlikely to be effective. The use of preventive measures will be affected by two things: how affected communities define their priorities regarding health and illness and the degree to which individuals think they can personally control or prevent illness. No matter how sound a preventive approach might be, if communities do not see the merits of a particular approach or if competing needs are prioritised higher, the intervention approaches will fail to some degree. Participation promotes selfawareness and confidence, causes people to examine their problems and to think positively about solutions.

\section{References}

Ahmed, M. (1978) Community participation, the heart of primary health care. Assignment Children 42, 80-99.

Bermejo, A. \& Bekui, A. (1993) Community participation in disease control. Social Science and Medicine 36, 1145-1150.

Chambers, R. (1992) Rural Appraisal: Rapid, relaxed and participatory. IDS Discussion Paper 311. Brighton: IDS.
Espino, F., Koops, V. \& Manderson, L. (2004) Community Participation and Tropical Disease Control in Resource-poor Settings. World Health Organization. TDR/STR/SEB/ST/04.1.

Klinkenberg, E., McCall, P.J., Hastings, I.A., Wilson, M.D., Amerasinghe, F.P. \& Donnelly, M.J. (2005) Malaria and irrigated crops, Accra, Ghana. Emerging Infectious Disease 11, 1290-1293.

Lane, J. (1995). Non-governmental organizations and participatory development: the concept in theory versus the concept in practice. In: N. Nelson and S. Wright (eds.), Power, participation development: Theory and practice. Intermediate Technology Publications, Southampton, Row, U.K., pp. 181-200.

Mboera, L.E.G. (1998) Decision analysis in malaria vector control programmes. Tanzania Health Research Bulletin 1 (2) 18-26.

Mboera, L.E.G., Rumisha, S.F., Senkoro, K.P., Mayala, B.K., Shayo, E.H \& Kisinza, W.N. (2007) Knowledge and health information communication. East African Journal of Public Health 3, 00-00 (in press).

Mukabana, W.R., Kannady, K., Kiama, G.M., Ijumba, J.N., Mathenge, E.M., Kiche, I., Nkwengulila, G., Mboera, L., Mtasiwa, D., Yamagata, Y., van Schayk, I., Knols, B.G.J., Lindsay, S.W., de Castro, M.C., Mshinda, H., Tanner, M., Fillinger, U. \& Killeen, G.F. (2006) Ecologists can enable communities to implement malaria vector control in Africa. Malaria Journal 5, 9.

Oakley, P. (1991) Understanding Participation. Project with People: the Practice of Participation in Rural Development. Geneva, International Labour Office, pp. 1-24.

Mogi, M., Okasawa, T., Miyagi, I., Sucharit, S., Tumrasvin, W., Deesin, T. \& Khamboonruang, C. (1986) Development and survival of Anopheline immatures (Diptera: Culicidae) in rice fields in Northern Thailand. Journal of Medical Entomology 23, 244-250.

Rajendraan, R. \& Reuben, R (1991) Evaluation of the water fern Azolla microphylla for mosquito population management in the rice-land agroecosystem of south India. Medical and Veterinary Entomology 5, 299-310.

Samba, E. (2001) The malaria burden and Africa. American Journal of Tropical Medicine and Hygiene 64 (Suppl 1-2) ii.

TNVS (2006) Private Sector Involvement in Public Health Delivery. A country Case Study: Tanzania National Voucher Scheme. Accessed at http:// www.njema.com, May 9, 2006. 
URT (2003) 2002 Population and Housing Census General Report. Central Census Office. National Bureau of Statistics, President's Office, Planning and Privatization. Government Printers, Tanzania, 203 pp.

van den Berg, H. \& Knols, B.G.J. (2006) The Farmer Field School: a method for enhancing the role of rural communities in malaria control. Malaria Journal 5, 3. doi:10.1 186/1475-2875-5-3.
WHO (2004) Global Strategic Framework for Integrated Vector Management. World Health Organization, Geneva.

Woelk, G.B. (1992) Cultural and structural influences in the community creation and participation in community health programmes. Social Science \& Medicine 35, 419-424. 